\title{
WORKER DISPLACEMENT, JOB SEARCH, AND REEMPLOYMENT: A TEMPORAL ANALYSIS OF REGIONAL STRUCTURAL CONDITIONS
}

\author{
John Adam Hill*
}

\begin{abstract}
This research developed a methodology for assessing regional structural changes across time based on the labor market outcomes of displaced workers. The investigation of changing regional structure requires that correlation between worker displacement and regional structural change be established. Establishing this connection is crucial, because it is the goal of this investigation to gain insight regarding changing regional structure from the labor market outcomes of displaced workers.

Census data was used to calculate reemployment rates and estimate a series of job-search equations for displaced workers. The estimates were used to decompose the differences in reemployment rates into components that are representative of (1) changes in reemployment linked to changing worker endowments and (2) changes in the reemployment rate linked to changing employer's perceptions about worker endowments or structure.
\end{abstract}

\section{INTRODUCTION}

Interest in and studies on displaced workers began during the automation scare in the late 1950's and early 1960's which, in turn, led to concerns regarding the intractability of unemployment (Seitchik, 1991). In the industrialized Midwest, such trends in automation and outsourcing continued to claim jobs, but a good share of worker dislocation was also the result of plant closings and disinvestment. Meanwhile, other regions experienced displacement from such events to a lesser degree. Illustrative of this is the South, which grew faster in recent decades than any other region in terms of employment rolls (Glickman and Glasmeier, 1989).

Still, growing regional economies are not immune from worker displacement. While the economy of the South experienced sectoral growth, this only offset the decline in investment and the resulting displacement elsewhere in the regional economy. This indicates that if one is to understand displacement, it is advantageous to consider labor market outcomes in a regional rather than a national context (Rodwin, 1989).

Divergent rates of displacement can be linked to unique regional events and performance. The catalyst for such displacements in the most recent years may be found in changes that are structural in nature (Seitchik, 1991). Various

*Assistant Professor, Northeastern State University, Tahlequah, OK. 
theories exist which explain why these structural changes arise and this research does not attempt synthesis of these divergent views. ${ }^{1}$ Instead, the purpose of this analysis is to offer a methodology to assess the changes in structure over time that these competing theories acknowledge.

It is important to clarify what is meant by the term "structure" as employed in this investigation. In this analysis, national or regional structure is concerned with the technical structure of the nation and regions during a particular period. The demands on national or regional labor markets by employers are a manifestation of this technical structure. As technological structure changes over time, so do the employer perceptions and their demands placed on skills and attributes of workers in national and regional labor markets (Carter, 1970). Therefore, when temporal differences in technical structure are discussed, these changes are denominated in terms of displacement and reemployment as they arise from changing employer perceptions.

\section{PRIOR INVESTIGATIONS}

The primary purpose of this analysis is to assess the temporal structural differences as manifested in the reemployment outcomes of displaced workers at the national level or in a specific region. To accomplish this, the job-search process (Ehrenberg and Smith, 1988; Lippmann and McCall, 1976) of displaced workers was investigated to reveal the determinants of reemployment opportunities and displacement attributes unique to the worker, the job from which he/she was displaced, the search for reemployment, and the particular timing of displacement. This is a preliminary step required to assess both regional and temporal structural differences. ${ }^{2}$

The assessment of regional structural change has received scant attention in regional theory and empirical analyses; presently, there exists three such methodologies for assessing temporal regional structural change: the calculation of gross regional product differentials, shift-share analysis, and input-output tabulations. These existing methodologies for assessing regional structural change rely heavily on economic conditions at the national level or depend on regional data which does not exist (Arcelus (1984), Bruno (1986), Connaughton and Madsen(1990), Esteban-Marquillas (1972), Herzog and Olsen (1977), Hewings (1985), Hoover and Giarratani (1984), Kochanowski (1989), Miernyk (1965), Pieter and Broesterhuizen (1986), Richardson (1972)). Instead, this methodology is a unique alternative to the existing methods designed to test regional structure as it does not rely on structural 
outcomes at the national level nor does it depend on the levels of output from each region or the nation.

\section{DATA}

\section{Displaced Worker Supplement to the Current Population Survey}

The data set for this investigation is comprised of microdata taken from the Displaced Worker Supplement (DWS) to the Current Population Survey (CPS) for the years 1986, 1988, 1990,1992, and 1994. The CPS contains a variety of variables unique to describing the predicament of the displaced worker. ${ }^{3}$ Additionally, the DWS contains variables relating to job loss and the post-displacement experience. The DWS also contains geographic codes that permit the inclusion of local labor market conditions and, thus, facilitate analysis of reemployment likelihood at the regional level.

This investigation employs race and sex variables to cull observations particular to white-males to eliminate any discrimination effects that might distort the regional structural conclusions of the decomposition technique described. ${ }^{4}$ Additionally, data that is used for tabulation in this study are restricted to workers who are seeking full-time rather than part-time reemployment. The rationale for this restriction is that regional structural conditions are better manifested in the labor market outcomes of workers seeking full-time reemployment than for those who do not seek full-time reemployment.

\section{Regional dimension of reemployment}

Table 1 provides information on the incidence of worker displacement and reemployment by Census Region as tabulated in the 1986, 1988, 1990, 1992, and 1994 DWS. This table lists reemployment rates for white-male displaced workers who either held or were seeking full-time employment. ${ }^{5}$ Reemployment rates are expressed as percents, and represent the reemployment status of workers displaced in the three previous years. ${ }^{6}$

Inspection of Table 1 reveals that the passage of time impacts each region differently in terms of reemployment likelihood as none of the reemployment rate differentials in Table 1 change by the same magnitude. This investigation examines these divergent reemployment rate differentials, concluding that unique regional forces are at work that impact reemployment likelihood. These temporal differences in reemployment rates are bifurcated between the job-search attributes possessed by displaced workers and regional structure. 


\section{TABLE 1}

Reemployment Rates of Displaced White-Male

Workers Seeking Full-time Employment ${ }^{2, b}$

\begin{tabular}{llllll}
\hline Region & 1986 & 1988 & 1990 & 1992 & 1994 \\
\hline United States & 71.37 & 77.38 & 78.1 & 66.72 & 73.93 \\
Northeast Census Region & 65.65 & 73.73 & 69.38 & 59.3 & 68.95 \\
Midwest Census Region & 70.63 & 76.14 & 69.68 & 66.4 & 76.52 \\
South Census Region & 75.67 & 79.36 & 84.92 & 72.33 & 75.99 \\
West Census Region & 69.59 & 77.95 & 83.78 & 66.46 & 73.88 \\
\hline
\end{tabular}

a Compiled from the CPS-DWS, utilizing population weights provided in the microdata.

${ }^{b}$ Reemployment rates include only those workers who were displaced 3 years prior to the DWS tabulation.

\section{ECONOMETRIC ESTIMATION}

To investigate the plight of displaced workers, two sets of estimates were obtained. The preliminary estimates concatenated all five aforementioned CPS-DWS data sets and were employed to assess whether or not regional labor market outcomes varied over time. Upon finding that the period of displacement impacted reemployment likelihood, ${ }^{7}$ a second round of estimates were obtained. This final set of regional equations made use of the same regressors included in the preliminary investigation, however, separate estimates were obtained for each of the DWS datasets.

This primary round of equations were estimated as follows. Letting the binary variable " $T$ " denote whether or not a displaced worker is reemployed full-time:

$$
T=\beta^{\prime} X
$$

where $\beta$ is a vector of parameter estimates and $X$ is a vector of individual, displaced job, job-search, and displacement timing characteristics. Equation (1) was estimated for each of the Census Regions and the aggregate United States as well as for each year of the DWS. An example of these equation estimates for the United States in 1986, 1988, 1990, 1992, and 1994 is provided in Table 2. Equivalent tables for the Northeast, South, Midwest, and West are available upon request from the author.

By conducting this aforementioned investigation using data on displaced labor, regional and national histories can be crafted that focus on changing 


\section{TABLE 2}

Primary Analysis: : Determinants of Employment for Displaced White Males in the United States

\begin{tabular}{|c|c|c|c|c|c|}
\hline Variable & 1986 & 1988 & 1990 & 1992 & 1994 \\
\hline Equation intercept & $2.3715^{* * *}$ & $3.3979 * * *$ & $2.5076^{* * *}$ & $2.491 * * * 2$ & $2.3741^{* * *}$ \\
\hline \multicolumn{6}{|l|}{ Worker Characteristics: } \\
\hline Age & $-.017^{*}$ & $-.0368^{* * *}$ & -.0138 & $-.0179 * *$ & $-.0173^{*}$ \\
\hline Age exceeding fifty & .00216 & -.00284 & .00175 & .000058 & -.00344 \\
\hline \multicolumn{6}{|l|}{ Education } \\
\hline High school graduate & $.579 * * *$ & .2372 & $.8784^{*}$ & $.4549^{* * * *}$ & $.671^{* * *}$ \\
\hline Up to four years of college & $.882^{* * *}$ & $.69 * * *$ & $.5781^{* * *}$ & $.8805^{* * *}$ & $.972^{* * *}$ \\
\hline More than four years of college & $1.2447^{* * *}$ & $.9636 * *$ & -.112 & $.825^{* * *} \quad 1$ & $1.444^{* * *}$ \\
\hline Married & $.4379 * * *$ & $.4394^{* * * *}$ & $.456^{* * *}$ & $.4219^{* * *}$ & $.553^{* * *}$ \\
\hline \multicolumn{6}{|l|}{ Occupation } \\
\hline Managerial or professional & .027 & .5021 & $1.0275^{* * * *}$ & -.3235 & .3115 \\
\hline Technical, sales or administrative & .2577 & .5365 & $.941^{* * *}$ & -.2206 & .3161 \\
\hline Precision production, craft or repair & -.2434 & .2934 & $.9125^{* * *}$ & $-.565^{* *}$ & -.0125 \\
\hline Operator, fabricator, or laborer & $-.4633^{*}$ & .2275 & $.649 * *$ & $-.5852^{* * * *}$ & .0615 \\
\hline \multicolumn{6}{|l|}{ Displaced Job Characteristics: } \\
\hline Lost job to plant closure & $.3765^{* * *}$ & $.5195^{* * *}$ & $.2896^{*}$ & $.3553^{* * *}$ & .1320 \\
\hline Received advanced notice of plant closure & $.3847^{* * *}$ & .0856 & -.1695 & .1404 & .1881 \\
\hline Tenure on displaced job & -.000131 & $.0227 * *$ & $-.033^{* *}$ & -.00402 & .0139 \\
\hline Weekly earnings on displaced job & .0179 & .0437 & -.0441 & .0108 & .00029 \\
\hline \multicolumn{6}{|l|}{ Search Characteristics: } \\
\hline Population in state of job search & -.00476 & -.00541 & -.00465 & .0102 & .0109 \\
\hline Unemployment rate in state of job search & $-.137^{* * * *}$ & $-.2228^{* * *}$ & $-.1792^{* *}$ & $-.1769^{* *}$ & $-.1708^{* * *}$ \\
\hline Job search executed in an urban area & .1344 & .1234 & $.4524^{* *}$ & .2004 & -.1108 \\
\hline Conducted job-search related move & $.4738^{* * *}$ & .2316 & $1.0696^{* * * *}$ & .1162 & .1081 \\
\hline Recipient of unemployment insurance & $-.5238^{* * *}$ & $-.8624^{* * *}$ & $-.9755^{* * *}$ & $-.4739 * * *$ & $.5708^{* * *}$ \\
\hline \multicolumn{6}{|l|}{ Region where job search was performed } \\
\hline Midwest & .1809 & $.625 * * *$ & -.1484 & .1552 & $.5209^{* * * *}$ \\
\hline South & $.547 * * *$ & $.7137^{* * * *}$ & $.6213^{* * *}$ & $.5534^{* * * *}$ & $.3737 * *$ \\
\hline West & .0808 & $.6143^{* * *}$ & $.5312^{* *}$ & $.3717^{* *}$ & $.6731^{* * *}$ \\
\hline \multicolumn{6}{|l|}{ Displacement Timing: } \\
\hline \multicolumn{6}{|l|}{ Year of Displacement } \\
\hline One year prior to survey & $-1.8219 * * *$ & $-2.0461^{* * *}$ & $-2.0206^{* * *}$ & $-1.6866^{* * *}$ & $-1.474^{* * *}$ \\
\hline Two years prior to survey & -.3028 & $-.3999 *$ & .0190 & $-.4484^{* * *}$ & .0463 \\
\hline$\overline{\mathbf{N}}$ & 1,773 & 1,613 & 1,305 & 2,018 & 1,496 \\
\hline
\end{tabular}

\footnotetext{
*t-test significant at the 0.10 level

**t-test significant at the 0.05 level

***t-test significant at the 0.01 level

2The log likelihood ratio test statistic is significant at the one percent level in each of the five models.

Unemployment figures are adjusted for percent displaced.
} 
reemployment opportunities over time, particularly between the years 1986 and 1994. These changes in reemployment opportunities can then be separated into structural and endowment effects at the national and regional level that contribute to the reemployment likelihood of displaced workers.

\section{DECOMPOSING TEMPORAL DIFFERENCES FOR THE NATION AND REGIONS}

Such estimates can be utilized to decompose regional differences in mean reemployment rates into two effects: one effect that is reflective of displaced worker characteristics (differences in the explanatory variable means) and the other effect reflective of employer perceptions about displaced worker characteristics or regional structure (differences in estimated parameters). The genesis for this approach is an analysis conducted by Herzog and Schlottmann (1995) which adapts a decomposition technique attributed to Oaxaca (1973) to the issue of job-market outcomes as affected by regional restructuring. The Herzog and Schlottmann (1995) methodology is designed to decompose a specific period's reemployment likelihood function into endowment components and structural components.

This analysis differs from both the Oaxaca (1973) and Herzog and Schlottmann (1995) studies in one important aspect. Reemployment likelihoods are decomposed within regions across periods as well as across regions within a period. With this approach, one is able to develop insights regarding changing structure in a particular region as well as the relative strength of a region in a particular time period.

\section{Decomposition methodology}

The predicted likelihood of reemployment is determined from the logistic equation:

$$
L_{m n}=\frac{1}{1+e^{-T_{m}}}
$$

where

$$
T_{m n}=\beta_{m}^{\prime} \bar{X}_{n} \text {. }
$$

In equation (3), $\beta_{m}$ is defined as a vector of parameters on the explanatory variables while $\bar{X}_{n}$ is a vector of explanatory variable means. ${ }^{8}$ These parameters and means are employed to obtain decomposition results on reemployment rate dif- 
ferentials. There are two sets of reemployment rate differentials which are decomposed into structural and endowment effects in this study:

1) those differentials between regions " $m$ " and " $n$ " for a particular year, and

2) those differentials between years " $m$ " and " $n$ " for a particular region.

In either case, $\mathrm{L}_{\mathrm{mn}}$ in equation (2) can be generally interpreted as the likelihood of reemployment for a worker endowed with " $n$ " characteristics who undertakes job-search within a labor market exhibiting " $m$ " structure, where " $m$ " and " $n$ " may be used to designate two distinct regions or two particular years between which the decomposition is conducted.

The difference in predicted likelihood of reemployment between " $\mathrm{m}$ " and " $n$ "9 can be decomposed into endowment effects, $E_{m, n}$ (differences between " $m$ " and " $n$ " in average worker attributes), and structural effects, $S_{m, n}$ (differences between " $m$ " and " $n$ " in employer perceptions about worker attributes). $S_{m, n}$ or the structural component, can be calculated as $L_{m, m}-L_{n, m}$ and $L_{m, n}-L_{n, n}{ }^{10}$ The former term represents the change in reemployment likelihood if an average worker of " $\mathrm{m}$ " characteristics is moved from " $\mathrm{n}$ " to " $\mathrm{m}$ " to undertake job-search. The latter estimate of $S_{m, n}$ is derived from parameter differentials between " $m$ " and " $n$ " in which the reemployment rate change is based upon the average characteristics that describe " $n$ " workers.

The choice between alternative estimates is arbitrary when deriving the endowment and structural effects. These alternative estimates can be explicitly considered within the decomposition by expressing $E_{m, n}$ and $S_{m, n}$ as weighted averages. ${ }^{11}$ In this regard,

$$
\begin{aligned}
& E_{m, n}=w\left(L_{n, m}-L_{n, n}\right)+(1-w)\left(L_{m, m}-L_{m, n}\right) \\
& S_{m, n}=w\left(L_{m, m}-L_{n, m}\right)+(1-w)\left(L_{m, n}-L_{n, n}\right)
\end{aligned}
$$

where " $w$ " $(0<w<1)$ is the weighting factor. In equations (4) and (5) the proportion of $L_{m, m}-L_{n, m}$ the predicted reemployment rate differential, assigned to $S_{m, n}$ (and conversely to $E_{m, n}$ ) varies with the value of the " $w$ " employed within the decomposition. Decomposition outcomes which are weighted more towards " $\mathrm{m}$ " or " $n$ " are avoided by applying a $w=.5 .^{12}$

The terms "endowment" and "structure" may not provide the best descriptors for what is determined in equations (4) and (5), however these terms are applied in a manner consistent with the interpretation of the Oaxaca (1973) procedure. $E_{m, n}$ and $S_{m, n}$ represent the respective portions of the reemployment 
rate differential between " $n$ " and " $m$ " attributable to differences in the explanatory variable means and to differences of estimated parameters, respectively. The differences in the estimated parameters, or structural effect, measure the added likelihood of securing reemployment in " $\mathrm{m}$ " as opposed to " $\mathrm{n}$ " for a representative displaced worker characterized by a given array of attributes. ${ }^{13}$ As noted by Herzog and Schlottmann (1995): "like structural unemployment, this effect measures, at least in part, the degree to which skills required for available jobs match those possessed by displaced workers seeking reemployment. Thus, this term represents a differential capacity (positive or negative) to reemploy additional displaced workers." (Herzog and Schlottmann, 1995).

Again, it is worthwhile to note that whether one is calculating structural differences between regions " $m$ " and " $n$ " for a certain time period or structural differences between time periods " $\mathrm{m}$ " and " $\mathrm{n}$ " for a specific region, the point of inception is the same. In either decomposition, $\beta_{\mathrm{m}}$ and $\beta_{\mathrm{n}}$ (the vectors of parameters on explanatory variables for " $\mathrm{m}$ " and " $\mathrm{n}$ ") along with $\bar{X}_{m}$ and $\bar{X}_{n}$ (the vectors of explanatory variable means for " $m$ " and " $n$ ") must be estimated. As stated previously, all of the estimates used to analyze regional structure across time can also be used to make interregional comparisons regarding structure.

\section{Analysis of Structure Components Between Regions}

Equations (4) and (5) are appropriate for calculating the endowment and structure components of reemployment rate differential between regions as seen in Herzog and Schlottmann (1995). Here, " $m$ " and " $n$ " indicate different United States Census Regions and $E_{m, n}$ and $S_{m, n}$ represent the portions of the reemployment rate differentials attributable to differences in the regional explanatory variable means and of the regional estimated parameters, respectively. The differences in the estimated parameters can be used to rank regions as to their relative strengths in providing reemployment opportunities for displaced workers.

Table 3 has been organized by the five years of assessment used in this analysis. Each panel contains the structural components by year of assessment, calculated from reemployment rate differentials determined from Table 1 and the parameters taken from the primary estimates illustrated by Table 2 . In these panels, the structural components in each region-row are ranked from 1 to 4 . A ranking of 4 indicates the greatest structural disadvantage and a ranking of 1 indicates the greatest structural advantage among the four regions.

Using these rankings, one can examine regional comparisons by considering the rankings within each region-column. The South is consistently ranked first in 


\section{TABLE 3}

Structural Components of Reemployment Rate Differentials Among Census Regions ${ }^{a}$ (White-males by region of displacement)

\begin{tabular}{|c|c|c|c|c|c|c|c|c|c|}
\hline \multirow[t]{5}{*}{1986} & \multirow{2}{*}{$\begin{array}{l}\text { Regions: } \\
\text { Northeast }\end{array}$} & \multicolumn{2}{|c|}{ Northeast } & \multicolumn{2}{|c|}{ Midwest } & \multicolumn{2}{|c|}{ South } & \multicolumn{2}{|c|}{ Weat } \\
\hline & & 0 & 2 & $*$ & & -9.79 & 1 & * & \\
\hline & Midwest & $*$ & & 0 & 2 & -4.88 & 1 & 1.88 & 3 \\
\hline & South & -9.79 & 2 & 4.88 & 4 & 0 & 3 & -42.91 & 1 \\
\hline & West & * & & -1.88 & 1 & 42.91 & 3 & 0 & 2 \\
\hline \multirow[t]{5}{*}{1988} & Rezions: & \multicolumn{2}{|c|}{ Northeast } & \multicolumn{2}{|c|}{ Midwest } & \multicolumn{2}{|c|}{ South } & \multicolumn{2}{|c|}{ West } \\
\hline & Northeast & 0 & 1 & $*$ & & $*$ & & $*$ & \\
\hline & Midwest & * & & 0 & 3 & -9.89 & 1 & -1.29 & 2 \\
\hline & South & * & & 9.89 & 2 & 0 & 1 & $*$ & \\
\hline & West & * & & 1.29 & 2 & $*$ & & 0 & 1 \\
\hline \multirow[t]{5}{*}{1990} & Regions: & \multicolumn{2}{|c|}{ Northeast } & \multicolumn{2}{|c|}{ Midwest } & \multicolumn{2}{|c|}{ South } & \multicolumn{2}{|c|}{ West } \\
\hline & Northeast & 0 & 3 & * & & -8.52 & 1 & -6.35 & 2 \\
\hline & Midwest & * & & 0 & 3 & -14.21 & 1 & -12.41 & 2 \\
\hline & South & 8.52 & 3 & 14.21 & 4 & 0 & 1 & 1.4 & 2 \\
\hline & West & 6.35 & 3 & 12.41 & 4 & -1.4 & 1 & 0 & 2 \\
\hline \multirow[t]{5}{*}{1992} & Regions: & \multicolumn{2}{|c|}{ Northeast } & \multicolumn{2}{|c|}{ Midwest } & \multicolumn{2}{|c|}{ South } & \multicolumn{2}{|c|}{ West } \\
\hline & Northeast & 0 & 4 & -1.07 & 3 & -10.63 & 1 & -7.29 & 2 \\
\hline & Midwest & 1.07 & 4 & 0 & 3 & -9.48 & 1 & -0.96 & 2 \\
\hline & South & 10.63 & 3 & 9.48 & 2 & 0 & 1 & 11.9 & 4 \\
\hline & West & 7.29 & 4 & 0.96 & 3 & -11.9 & 1 & 0 & 2 \\
\hline \multirow[t]{5}{*}{1994} & Rerions: & \multicolumn{2}{|c|}{ Northeast } & \multicolumn{2}{|c|}{ Midwest } & \multicolumn{2}{|c|}{ South } & \multicolumn{2}{|c|}{ West } \\
\hline & Northeast & 0 & 4 & -6.19 & 3 & -7.11 & 1 & -6.99 & 2 \\
\hline & Midwest & 6.19 & 4 & 0 & 2 & 0.55 & 3 & -1.27 & 1 \\
\hline & South & 7.11 & 3 & -0.55 & 1 & 0 & 2 & $*$ & \\
\hline & West & 6.99 & 3 & 1.27 & 2 & * & & 0 & 1 \\
\hline
\end{tabular}

2The decomposition is based on equation (5) with $w=.5$

1988, 1990, and 1992, ${ }^{14}$ and the Northeast is ranked third in 1990 and second in 1986 among the four regions sampled. Lastly, the West is clearly ranked second among census regions in 1990.

Some results make it difficult to discuss regional structure. In 1988 and 1990 , the Midwest suffered from greater structural impediments to reemployment than the other census regions. However, in 1992 and 1994 this distinction is passed to the Northeast. Given this recent situation in the Northeast in both these years, it is concluded that the economic structure of other regions is more conducive to the reemployment of displaced workers than is the case in the Northeast. 
Though the decomposition results in Table 3 can be used to assess relative regional strengths for a single period, they cannot be used to examine temporal changes. The decomposition statistics contained in Table 3 only analyze structure between regions for one period, hence no opportunity exists for assessing regional structural change across time. Recognizing this, the aforementioned methodology must be modified to accommodate the assessment of temporal structural change.

\section{Analysis of Structure Components Over Time}

The general equations introduced in (4) and (5) can also be used to calculate the endowment and structure components of reemployment rate differentials between time periods in a given region. Unlike in the previous section, " $\mathrm{m}$ " and " $n$ " now denote different time periods. Therefore, $E_{m, n}$ and $S_{m, n}$ represent the respective portions of the regional reemployment rate change attributable to temporal differences in the explanatory variable means and the estimated parameters, respectively. The former reflects changes in reemployment potential within a region attributable to changing endowments. Alternatively, the latter can be used to assess changing perceptions of regional employers regarding the skills of displaced workers.

$\mathrm{S}_{\mathrm{m}, \mathrm{n}}$ is derived from the differences between estimated parameters and illustrates changing employer's perceptions of worker attributes over time. Negative parameter differences indicate that perceptions about displaced worker attributes are hindering the worker from gaining reemployment as the regional or national economy changes over time. Therefore, the structural effect captured by $\mathrm{S}_{\mathrm{m}, \mathrm{n}}$ illustrates the salable aspect of the skills possessed by displaced workers seeking reemployment, given the changing structure of the region. ${ }^{15}$

Again, Table 1 contains yearly reemployment rates among white male displaced workers seeking full-time employment. The differences in regional reemployment rates, along with the reemployment rates for the nation, are decomposed (with $w=0.5$ ) into endowment and structural components through application of the aforementioned methodology, generally delineated in equations (4) and (5).

The results of the decomposition are presented in Table 4. This table is divided into five sections with each panel representing the divergent national and regional economies and the respective national or regional ability to reemploy displaced workers as time changes. For example, reemployment prospects for displaced workers improved by 6.01 percent at the national level between 1986 to 1988. Furthermore, these increased displaced worker reemployment odds for 1988 (versus 1986) are bolstered by improved worker endowments at both the 
national and regional levels. According to Table 4, worker endowments in 1988 improve the odds of reemployment at the national level by 4.64 percent. Also, changing national structure increases the chances of displaced worker reemployment by 1.37 percent in 1988 when compared to reemployment odds for 1986.

Table 4 can also be used to perform similar analysis by region for a particular year. Between 1986 and 1988, reemployment rates improved for all four Census Regions investigated and Table 4 shows that regional endowments and structure uniquely explained these changing reemployment rates. In all regions, displaced worker endowments contributed improved reemployment rates between 1986 and 1988. For the Northeast, Midwest, and West, such favorable endowment effects were further strengthened by changes in regional structure. Conversely, changes in regional structure over this period worked to the disadvantage of displaced workers in the South.

Table 4 also allows the reader to chart changes in regional endowments over time. For example, changing endowments work to the advantage of displaced workers in the South over the period 1986-1990. After 1990, however, endowment changes work to their disadvantage, and thus tend to diminish reemployment likelihoods. Similar trends can also be observed in other regions.

Alternatively, Table 4 can be employed to track changing regional structure across time. For instance, the changing perceptions of employers in the South reduce the odds of displaced worker reemployment between 1986 and 1988, but subsequently increase these odds between 1988 and 1990. This pattern of negative and positive structural effects is again observed between 1990 and 1994. Finally, it is important to note the complementary role of information provided in Tables 3 and 4. In this regard, the rankings in Table 3 can be used in tandem with the information in Table 4 to assess regional structural changes, both "relative" to conditions elsewhere and over time.

\section{vI. CONCLUSION}

With regard to answering questions about the impact of regional structure on labor markets, existing methodologies provide little or no relevant information. This analysis provides an alternative means of assessing regional structural change and avoids the problems inherent in shift-share analysis, input-output studies, and accounts. This methodology sidesteps the major shortcomings of these aforementioned assessment tools by eliminating the need for detailed regional data, and permitting regional structural estimates to vary independent of some predetermined reference economy. Instead, this method of assessment 


\section{TABLE 4}

Decomposition of Reemployment Likelihood for the Nation and Census Region

(White-males displaced between 1984 and 1993 seeking full-time reemployment)

Reemployment rates differentials (by region)

$1986-1988$

$1988-1990$

$1990-1992$

$1992-1994$

\section{United Stotes}

\begin{tabular}{lllrr}
\hline $\begin{array}{l}\text { Difference in Mean Reemployment Rates (\%) } \\
\text { Portion Attributable to Differences in: }\end{array}$ & 6.01 & 0.72 & -11.38 & 7.22 \\
Average Characteristics (Endowment) & 4.64 & 0.55 & -0.88 & 11.18 \\
Equation Parameters (Structure) & 1.37 & 0.17 & -10.50 & -3.96
\end{tabular}

Northeast Ceases Revion

\begin{tabular}{llrrr}
\hline $\begin{array}{l}\text { Difference in Mean Reemployment Rates (\%) } \\
\text { Portion Attributable to Differences in: }\end{array}$ & 8.08 & -4.35 & -10.05 & 9.62 \\
$\quad$ Average Characteristics (Endowment) & 7.97 & -1.17 & 3.22 & 20.08 \\
Equation Parameters (Structure) & 0.10 & -3.18 & -13.27 & -10.46
\end{tabular}

Midweat Census Rexion

\begin{tabular}{lllll}
\hline Difference in Mean Reemployment Rates (\%) & 5.51 & -6.46 & -3.28 & 10.12
\end{tabular}

Portion Attributable to Differences in:

$\begin{array}{lrrrr}\text { Average Characteristics (Endowment) } & 5.15 & 1.05 & 0.06 & -24.10 \\ \text { Equation Parameters (Structure) } & 0.37 & -7.51 & -3.34 & 34.22\end{array}$

\section{South Census Revion}

\begin{tabular}{|c|c|c|c|c|}
\hline Difference in Mean Reemployment Rates (\%) & 3.70 & 5.56 & -12.59 & 3.66 \\
\hline \multicolumn{5}{|l|}{ Portion Attributable to Differences in: } \\
\hline Average Characteristics (Endowment) & 5.64 & 1.53 & -1.13 & -5.40 \\
\hline Equation Parameters (Structure) & -1.94 & 4.03 & -11.46 & 9.06 \\
\hline \multicolumn{5}{|l|}{ Weat Census Rerion } \\
\hline Difference in Mean Reemployment Rates (\%) & 8.37 & 5.83 & -17.32 & 7.42 \\
\hline \multicolumn{5}{|l|}{ Portion Attributable to Differences in: } \\
\hline Average Characteristics (Endowment) & 3.29 & 20.63 & -9.32 & 8.12 \\
\hline Equation Parameters (Structure) & 5.07 & -14.80 & -8.00 & -0.71 \\
\hline
\end{tabular}

2The decomposition results were calculated based on the parameters estimated in Table 2.

'The decomposition is based on equations (4) and (5) with $w=.5$

utilizes the characteristics of those displaced workers who were casualties of structural change within a particular region or the nation.

The structural components from the interregional decomposition and the temporal decomposition yielded by this study provide valuable insights that can be utilized by policy makers. When applied concurrently, the two sets of 
explanatory variable parameter differences permit one to assess regional structure across space and over time.

For example, consider the structural position of four census regions between 1990 and 1992. During this period, employer's perceptions of displaced worker characteristics worsened in all regions, i.e., changes in regional structure reduced the reemployment likelihood of displaced workers between 1990 and 1992. These temporal structural components indicate that government assistance should be made available to displaced workers in each region. Of the four regions in question, it would be desirable to know which region had experienced the greatest structural setback and would thus need the greatest amount of government assistance. However, if this public policy is designed using only the temporal structural components, nothing can be said with regard to which region is faring the worst. This limitation is overcome if the interregional structural components are applied alongside temporal structural components.

The interregional structural components conclusively indicate that the South has the best structure in both 1990 and 1992, relative to the other census regions examined in this inquiry. Also, these interregional structural components indicate that the West followed the South in relative structural strength in both 1990 and 1992. Lastly, the interregional structural components for the Midwest and Northeast suggest that these two regions have fared the worst in terms of relative structure. It is important to note that, like the temporal structural components, the interregional structural components offer little to the policy maker when used in isolation. While these results indicate that the South is the "best" and the Midwest and Northeast are the "worst" in terms of their ability to reemploy displaced workers, the results say nothing about improving or declining regional structure over time. To use only these rankings, one might be tempted to offer all government assistance to the Midwest and Northeast, some to the West, and none to the South since it is structurally superior, relative to the other regions.

When both sets of decompositions are applied jointly, the policy recommendations are clear. First, all regions need assistance because of the increasingly poor perceptions that employers have regarding displaced worker characteristics, i.e., the decline in structure in all regions between 1990 and 1992. Second, structural impediments to the reemployment of displaced workers are greater in the Midwest and Northeast during 1990 and 1992. Thus, the Midwest and Northeast need more government assistance than the West and the South.

These temporal and interregional structural components provide general policy information by indicating which regions need assistance. The results are suitable for developing regional policy in all years and regions assessed in this study, which may be used to recommend and defend policy action or inaction. 


\section{ENDNOTES}

1. Ascribing to the post-industrial thesis, one assumes that structural changes occur uniformly as the nation proceeds to an advanced economic state. Also, random regional structural changes are the result of a dynamic economy where there is growth in some regions relative to decline experienced in others (Rodwin, 1989, 13).

2. These attribute classes are utilized throughout this investigation.

3. Variables that are included in the CPS that are relevant to the model proposed for estimation include, but need not limited to, worker characteristics such as race, sex, age, education, occupation, and family status.

4. The motive for the omission of this class of displaced workers is that this decomposition technique was originally used to assess discrimination by race and sex in a study conducted by Oaxaca (1973). By eliminating minority cohorts, discrimination effects are expunged from the final results.

5. Full-time employment is defined as 35 hours of work per week or more.

6. As the final analyses in this study deals only with the full-time white-male cohort, estimations deal exclusively with the reemployment of workers summarized in Table 1.

7. Preliminary logit estimation followed the form:

$$
T=\beta^{\prime} X+\delta_{1}+\delta_{2}+\delta_{3}+\delta_{4} .
$$

In this statement, $T$ is a vector of binomial job-search outcomes, $\beta$ is a vector of characteristic coefficients on $\mathrm{X}$, which is a vector of job-search, individual, and displaced job characteristics. The binary regressors $\delta_{1}$ through $\delta_{4}$ represent four of five years of displacement assessment that will be used in this study to investigate temporal structural change. To analyze regional reemployment likelihood relative to 1986, the first year of assessment, the above model will be estimated for the United States and the four Census regions: Northeast, South, Midwest, and West.

The purpose of the binary regressors is to introduce a time pattern of reemployment likelihood into these preliminary models that will be estimated for each region and the nation. In these estimated equations, endowments or characteristics are allowed to change over time and the structure or coefficients are assumed to be stable over time. The resulting interpretation is that $\delta_{1}$ through $\delta_{4}$, which represent the year of displacement assessment, capture temporal changes in regional reemployment likelihood that cannot be assigned to changes in characteristics. For example, if the estimation of the above model for a region yields the result: $\delta_{1}>\delta_{2}>\delta_{3}>\delta_{4}>0$, then one could conclude that reemployment 
likelihood increases over time after controlling for temporal endowment changes. This demonstrated change in reemployment likelihood is attributed to structural change within the region over time. Comparisons between the Census regions and the nation are conducted using the time patterns exhibited by these estimated $\delta$ coefficients.

8. These characteristic parameters and means, $\beta_{\mathrm{m}}$ and $\bar{X}_{n}$, were calculated for the nation and regions by years of assessment. Also, $\beta_{\mathrm{n}}$ and $\bar{X}_{m}$, which are needed for the decomposition, were also calculated.

9. The likelihood of reemployment in " $m$ " is $L_{m, m}$ and the likelihood of reemployment in " $n$ " is $L_{n, n}$, hence $L_{m, m}-L_{n, n}$ is the difference in predicted likelihood of reemployment between " $m$ " and " $n$ ".

10. Analogous estimates of $E_{m, n}$ are $L_{n, m}-L_{n, n}$ and $L_{m, m}-L_{m, n,}$ respectively .

11. The estimates of $L_{m, m}, L_{n, n}$ do not necessarily equal the difference in reemployment rates, $R_{m}-R_{n}$, between " $m$ " and " $n$ ". Therefore, estimates of $E_{m, n}$ and $S_{m, n}$ are normalized as $\alpha E_{m, n}$ and $\alpha S_{m, n}$ where $\alpha=\left(R_{m}-R_{n}\right) /\left(L_{m, m}-L_{n, n}\right)$. Furthermore, when $\alpha$ takes on a negative value, $S_{m, n}$ and $E_{m, n}$ have little meaning regarding structural or endowment effects and these decompositions are eliminated from this study.

12. Sensitivity tests were conducted that employed weights of zero and one, permitting one to scrutinize the role of different weights on decomposition outcomes.

13. Of course, this effect is dependent on the weight, $w$, in equation (5).

14. This result corroborates the findings of Herzog and Schlottmann (1995).

15. Likewise, negative characteristic mean differences indicate that changing worker attributes hinder the displaced worker's chances of reemployment over time.

\section{REFERENCES}

Arcelus, Francisco J. "An Extension of Shift-Share Analysis." Growth and Change, vol. 15, no. 1, January 1984, p. 3-8.

Bruno, Roberto. "Problems of Comparability of Input-Output Tables over a Period of Time." in Alfred Franz and Norbert Rainer (eds.) Problems of Compilation of Input-Output Tables, Herstellung, Austria: Druckerei Gobitschek and Co., 1986.

Bureau of the Census. 1986. "Current Population Survey, January 1986: Displaced Workers, Technical Documentation CPS 86-1," Washington, D.C. 
Bureau of the Census. 1988. "Current Population Survey, January 1988:

Displaced Workers, Technical Documentation CPS 88-1," Washington, D.C.

Bureau of the Census. 1990. "Current Population Survey, January 1990:

Displaced Workers, Technical Documenttion CPS 90-1," Washington, D.C.

Bureau of the Census. 1992. "Current Population Survey, January 1992:

Displaced Workers, Technical Documentation CPS 92-1," Washington, D.C.

Bureau of the Census. 1994. "Current Population Survey, January 1994:

Displaced Workers, Technical Documentation CPS 94-2," Washington, D.C.

Carter, Anne P. Structural Change in the American Economy. Cambridge, MA: Harvard University Press, 1970.

Ehrenberg, Ronald G. and Robert S. Smith. Modern Labor Economics: Theory and Public Policy, 3rd ed. Glenview, IL: Scott, Foresman, and Company, 1988.

Esteban-Marguillas, J. M. “A Reinterpretation of Shift-Share Analysis." Regional and Urban Economics, vol. 2, 1972, pp. 9-16.

Glickman, Norman J. and Amy K. Glasmeier. "The International Economy and The American South," in Lloyd Rodwin and Hidehiko Sazanami (eds.) Deindustrialization and Regional Economic Transformation: The Experience of the United States, Boston: Unwin Hyman, Inc., 1989.

Herzog, Jr., Henry W. and Richard Olsen. "Shift-Share Analysis Revisited: The Allocation Effect and the Stability of Regional Structure." Journal of Regional Science, vol. 17, no. 3, December 1977, pp. 441-454.

Herzog, Jr., Henry W. and Alan M. Schlottmann. "Worker Displacement and Job-Search: A Regional Analysis of Structural Impediments of Reemployment." Journal of Regional Studies, vol. 35, no. 4, 1995, pp. 553-577.

Hewings, Geoffrey J. D. Regional Input-Output Analysis. Beverly Hills, CA: Sage Publications, 1985.

Hoover, Edgar M. and Frank Giarratani. An Introduction to Regional Economics, 2nd ed. New York: Alfred A. Knopf, 1984.

Kochanowski, Paul, Wayne Bartholomew, and Paul Joray. "The Shift-Share Methodology: Deficiencies and Proposed Remedies." Regional Science Perspectives, vol. 19 , no. 1,1989 , pp. $65-88$.

Lippman, Steven A. and John J. McCall. "The Economics of Job Search: A Survey," Economic Inquiry, vol. 14, June 1976, pp. 155-189.

Oaxaca, R. "Male-Female Wage Differentials in Urban Labor Markets." International Economic Review, vol. 14, no. 3, October 1973, pp. 693-709. 
Pieter, $\mathrm{Al}$ and Guss Broesterhuizen. "Comparability of Input-Output Tables in Time." in Alfred Franz and Norbert Rainer (eds.) Problems of Compilation of Input-Output Tables, Herstellung, Austria: Druckerei Gobitschek and Co., 1986.

Richardson, Harry W. Input Output and Regional Economics. New York: John Wiley and Sons, 1972.

Rodwin, Lloyd. "Deindustrialization and Regional Economic Transformation," in Lloyd Rodwin and Hidehiko Sazanami (eds.) Deindustrialization and Regional Economic Transformation: The Experience of the United States. Boston: Unwin Hyman, Inc., 1989.

Seitchik, Adam. "Who Are Displaced Workers?" in John T. Addison (ed.) Job Displacement: Consequences and Implications for Policy. Detroit, MI: Wayne State University Press, 1991. 